REVIEW ARTICLE

Year : 2012 | Volume : 11 | Issue : 3 | Page : 125--130

\title{
Review of the publications of the Nigeria national blindness survey: Methodology, prevalence, causes of blindness and visual impairment and outcome of cataract surgery
}

M Mansur Rabiu ${ }^{1}$, Fatima Kyari ${ }^{2}$, Christian Ezelum ${ }^{3}$, Elizabeth Elhassan ${ }^{4}$, Safiya Sanda ${ }^{5}$, Gudlavalleti V. S. Murthy ${ }^{6}$, Selvaraj Sivasubramaniam ${ }^{6}$, Clare Glibert $^{6}$, MM Abdull ${ }^{7}$, A Abiose $^{8}$, O Bankole $^{9}$, G Entekume ${ }^{10}$, Faal $^{11}$, A Imam ${ }^{12}$, Lee Pak Sang ${ }^{13}$, Tafida Abubakar $^{14}$,

${ }^{1}$ Department of Community Ophthalmology, National Eye Centre, Kaduna, Nigeria

2 College of Health Sciences, University of Abuja, Nigeria

${ }^{3}$ Anambra State University Teaching Hospital, Amaku, Awka, Nigeria

${ }^{4}$ Sightsavers West Africa Regional Office, Dakar, Senegal

${ }^{5}$ Sighsavers, Nigeria Country Office, Kaduna, Nigeria

${ }^{6}$ International Centre for Eye Health, London School of Hygiene and Tropical Medicine, London, United Kingdom

${ }^{7}$ Abubakar Tafawa Balewa University Teaching Hospital, Bauchi, Nigeria

8 International Agency for Prevention of Blindness Africa Region, Ibadan, Nigeria

9 Department of Ophthalmology, Lions Eye Centre, Isolo Hospital, Lagos, Nigeria

10 Vision Health Services, Ikeja, Lagos, Nigeria

11 Sightsavers West Africa Regioanl Office, Accra, Ghana

12 Ministry of Health, Mina, Nigeria

13 Institute of Ophthalmology, London, United Kingdom

${ }^{14}$ Ministry of Health, Dutse, Jigawa State, Nigeria

\section{Correspondence Address:}

Gudlavalleti V. S. Murthy

International Centre for Eye Health, London School of Hygiene and Tropical Medicine, Keppel Street, London-WC1E7HT United Kingdom

\section{Abstract}

This is a review of the major publications from the Nigeria national blindness survey in order to highlight major findings and challenges of eye care in Nigeria. The review summarizes methodology and key findings. Survey publications on methodology, prevalence and causes of visual impairment and outcome of cataract surgery were retrieved, reviewed and relevant data extracted, reported and discussed. The study was the largest and more detailed eye survey in Nigeria (15,375 people 40 years and older recruited). Participants had detailed eye examination including visual acuity, autorefractokeratometry, A- scan biometry, visual field and basic eye examination. Cause(s) of visual impairment in each eye using WHO algorithm was determined among participants with vision < 6/12. Some of the participants also had qualitative questions on barriers to uptake of services, quality of life and visual function. Major highlights of the results as contained in the publications include a high prevalence of blindness with $4.2 \%$ (95\% Cl: $3.8-4.6 \%$;), of the study population having blindness (using presenting vision (PVA)) even with best correction the prevalence was 3.4\% (95\% Cl: $3.0-3.8 \%$. The prevalence of SVI using PVA was $1.5 \%$ (95\% Cl: $1.3-1.7 \%)$.and with best correction $0.8 \%$ (95\% $\mathrm{Cl}: 0.7-1.0 \%)$. Blindness varied by age groups, sex, literacy level and geopolitical zone. Furthermore, $84 \%$ of blindness was due to avoidable causes with cataract responsible for $43 \%$ of blindness, glaucoma $16.7 \%$, uncorrected aphakia $8.4 \%$ and corneal opacity $7.9 \%$. Of the total 538 eyes that had cataract surgery procedures, $42.7 \%$ had couching and the remaining had cataract surgery, but only $41.4 \%$ of cataract operated eyes had IOL surgery. Outcome of cataract surgery was good at presentation for only $30.8 \%$ of eyes ( 84 eyes) which improved to $56.8 \%$ with correction. The possible remedy for the high burden of needless blindness and harmful eye health practices in Nigeria are discussed.

How to cite this article:

Rabiu M M, Kyari F, Ezelum C, Elhassan E, Sanda S, Murthy GV, Sivasubramaniam S, Glibert C, Abdull M M, Abiose A, Bankole O, Entekume G, Faal H, Imam A, Sang LP, Abubakar T. Review of the publications of the Nigeria national blindness survey: Methodology, prevalence, causes of blindness and visual impairment and outcome of cataract surgery.Ann Afr Med 2012;11:125-130

\section{How to cite this URL:}

Rabiu M M, Kyari F, Ezelum C, Elhassan E, Sanda S, Murthy GV, Sivasubramaniam S, Glibert C, Abdull M M, Abiose A, Bankole O, Entekume G, Faal H, Imam A, Sang LP, Abubakar T. Review of the publications of the Nigeria national blindness survey: Methodology, prevalence, causes of blindness and visual impairment and outcome of cataract surgery. Ann Afr Med [serial online] 2012 [cited 2017 Oct 26 ]:11:125-130

Available from: http://www.annalsafrmed.org/text.asp?2012/11/3/125/96859

\section{Full Text}

\section{Introduction}

The World Health Organization (WHO) estimates that globally there are 39 million blind people and another 285 million are visually impaired. [1] Africa accounts for 15\% of blindness. Almost $80 \%$ of the causes are either preventable or treatable. [1] Blindness has recently been shown to have a major economic impact through lost productivity, [2],[3],[4] and eye care programs giving a high economic rate of return. [2],[3]

There is paucity of survey data from West and Central Africa where some of the poorest countries in the world are located. As poverty is closely associated with blindness, [5] it is likely that the age-specific prevalence of blindness in West Africa is higher than in industrialized countries and in Asia. In response to this, a national survey of blindness and visual impairment was undertaken in Nigeria, the largest country in Africa (population of 140 million inhabitants in 2006). [6] The objectives of the survey were to determine the prevalence, causes and magnitude of blindness and visual impairment and risk factors in individuals aged $\geq 40$ years; and to obtain information on cataract surgical services,

This paper presents a summary of the main findings of the survey as it relates the methodology, prevalence, causes of blindness and visual impairment and outcome of cataract surgery, as published across 5 journals, this is meant to provide wider dissemination of the survey results. [7],[8],[9],[10],[11]

\section{Materials and Methods}


The survey was conducted by two teams over a 30 -month period from 2005 to 2007 . An overall sample of 15,375 persons aged $\geq 40$ years was calculated. The study population was selected by multi-stage, stratified cluster random sampling, with probability-proportional-to-size procedures.

A total of 50 participants aged $\geq 40$ years were enumerated in each of the study clusters.

Examination procedures

Each individual was examined at a center organized within the community where an ophthalmic nurse recorded the height, weight and blood pressure of all participants using a digital wrist BP machine (OMRON).

Visual acuity testing

The ophthalmic nurse measured unaided distance visual acuity (VA) using a reduced logMAR E chart.

Refractive and keratometric readings were recorded in each eye using an autorefracto-keratometer (Takagi ARKM-100). All participants with VA <6/12 in one/ both eyes had their VA retested using their refractive readings. All participants also had their ocular dimensions measured using an A-ultrasound scan (Bioline Biometer) and had their visual field fields assessed using the N-30 screening mode (Humphrey FDT analyzer). Participants who failed the visual field screening test were retested using threshold visual field testing.

Eye examination

The lens was graded using Mehra-Minassian (MM) lens opacity grading system. [12] The posterior segment was assessed through an undilated pupil with a direct ophthalmoscope. The retina was also assessed for vascular retinopathy and other pathologies.

Detailed examination by a second ophthalmologist was done if participants had VA <6/12 in one/ both eyes; any abnormality suggestive of glaucoma (i.e CDR of $>0.6$; CDR asymmetry of $>0.2$ or presence of disc splinter hemorrhages) and every 7 th participant regardless of vision.

Grading of lens opacities was repeated using the WHO lens grading system. [13] Optic discs were re-examined to assess the vertical CDR, asymmetry, disc notching and splinter hemorrhages. Posterior segments were examined for retinal pathology.

A cause for visual loss was assigned if VA was $<6 / 12$ in one/ both eyes. All abnormalities that could contribute to visual loss were identified. One principal cause for each eye, followed by one cause for the person, was identified, according to WHO criteria. An underlying 'pathology' was also determined e.g. age-related, surgical complication, trachoma, etc.

Ethical issues and quality assurance

Ethical approval was obtained from the Ethics Committee of the London School of Hygiene and Tropical Medicine. The Federal Ministry of Health approved the survey. Witnessed, oral consent was obtained from community leaders, and participants. All participants with visual impairment requiring investigation or treatment were referred to the nearest eye facility.

Quality of the survey was ensured through periodic training and retraining sessions - including inter-observer agreement, regular calibration of survey equipment, and supervision of field activities.

\section{Results}

The results obtained as published in the papers is hereby summarized. A total of 15,122 persons aged $>40$ years were enumerated, and 13,599 ( $89.9 \%)$ examined in 305 of 310 identified clusters. Response rates were similar across GPZs and ranged from $88.2 \%$ to $93.5 \%$. The age and sex profile of those enumerated and those examined were similar [Table 1]. More than half of those examined were females (54\%.; [Table 1]). $\{$ Table 1$\}$

Prevalence and causes of blindness and visual impairment

The prevalence of blindness (VA<3/60 in the better eye) using presenting VA (PVA) was 4.2\% (95\% Cl: 3.8-4.6\%), but with best corrected VA (BCVA) it was 3.4\% (95\% CI: 3.0-3.8\%). The prevalence of severe visual impairment (VA<6/60 - 3/60; SVI) was 1.5\% (95\% Cl: $1.3-1.7 \%)$ and with BCVA it was $0.8 \%$ (95\% Cl: $0.7-1.0 \%)$ [Table 2]. Prevalence of blindness among those aged $\geq 50$ years was $5.5 \%$. All age estimated prevalence of blindness is $0.78 \%$. $\{$ Table 2$\}$

The magnitude of blindness varied across the country. The North West (NW) GPZ harbors the largest number of blind adults (28.6\%) because of high prevalence and large population. The survey estimated that a total 4.25 million adults aged $40 \geq$ years suffer moderate $\mathrm{VI}$ or SVI or blindness.

Cataract was the most common cause of blindness, (43\%), followed by glaucoma (16.7\%) [Table 3]. The underlying 'pathology' of blindness were age-related (73.2\%), measles, use of traditional eye medicines, and vitamin A deficiency (3.7\%), trachoma (4.2\%) and onchocerciasis (1.1\%). Overall, $84 \%$ of blindness was 'avoidable'. Major causes of visual impairment (PVA of $6 / 18$ to $3 / 60$ in the better eye) were uncorrected refractive error (62\%), followed by cataract (22.1\%) and uncorrected aphakia (3.3\%) [Table 3]. \{Table 3$\}$

All the common causes of blindness increased significantly with age. Females had nearly twice the risk of having PVA $<6 / 60$ due to cataract compared with males. Poor literacy was also associated with a higher risk of vision loss from cataract and refractive errors. Prevalence of vision loss from cataract was significantly lower in South-West (SW) and Sahel region had highest risk of cataract blindness. Trachoma was most prevalent in Sudan savannah while onchocerciasis was only present in Guinea savannah and rain forest.

Functional low vision

Using WHO [14] definition for functional low vision (FLV)), the crude FLV prevalence was 3.5\%, (95\% Cl: $3.1-3.9 \%)$ and age-sex standardized prevalence was 2.7\% (95\% Cl: $2.4-3.1 \%)$. 74 participants with FLV had perception of light only in one eye and 227 were classified as blind using the WHO definition. Glaucoma accounted for $26.5 \%$ of FLV, corneal opacity ( $21.5 \%$ ) and age-related macular degeneration (11\%). Only age was a constant risk factor for FLV in multivariate regression analysis.

Cataract surgery outcomes and standard IOLs

Among the 583 eyes (412 people) that underwent a procedure for cataract, only 273 eyes (181 persons) underwent formal cataract surgery, while 249 eyes (154 persons) underwent traditional treatment, undertaken by non-medical healers (couching). Surgery on the remaining eyes had been undertaken following trauma and so was excluded from the analysis.

It was observed that there was a significant change in surgical practice of cataract surgery in Nigeria over the past decade. The change in the surgical procedures has occurred rapidly [Figure 1]. Over the past three years, a higher proportion of cataract surgery uses an IOL implant. This was also accompanied with better visual outcomes among those undergoing IOL implant surgery [Table 4]. It was also observed that couching is very common in Nigeria and $42.7 \%$ of all cataract operated eyes were couched. This was accompanied by poor visual outcomes [Table 4].\{Figure 1\}\{Table 4\}

Biometry data obtained from the normative 1:7 participants revealed that the mean IOL power (an A constant 118.0) needed to achieve a post-operative refractive error of $-1.0 \mathrm{D}$ was $20.6 \mathrm{D}$ (SD +/-2.2D, range 10 to $30 \mathrm{D}$ ). It is estimated that about $71.4 \%$ of eyes will achieve a postoperative refraction of $-2.0 \mathrm{D}$ to emmetropia with posterior chamber IOL powers 20,21 , $22 \mathrm{D}$ assuming an 'A' constant of 118.0

\section{Discussion}


Few developing countries with large population as Nigeria have conducted a national survey on blindness to allow for appropriate comparison. In India, [15] the national estimated prevalence of $4.5 \%$ for similar age groups was similar to that of Nigeria, while in Pakistan (2003), it was $5.1 \%$ among those $\geq 40$ years. [16] In Africa, the only large country that recently conducted national blindness survey was Ethiopia which reported an all age prevalence of $1.6 \%$. [17] As in all these studies, avoidable causes of blindness were responsible for more than $2 / 3$ of blindness.

Although our study found that the prevalence of blindness is only $60-75 \%$ of WHO projection, [18] these figures are still alarming, as there are estimated to be over 1 million blind and another 3 million people with visual impairment.

The high prevalence of blindness/visual impairment in Nigeria is attributed to many factors including inadequate, ineffective and mal-distributed human resources. Even though the number of ophthalmologists in Nigeria (about 400; approximately one for every 350,000 people [19]) exceeds the minimum recommended by the West Africa Health Organization, about $80 \%$ are based in urban areas whereas over $70 \%$ of the Nigerian population live in rural areas. [6] There are also marked inequalities between regions e.g SW GPZ has four times the number of health workers $(16,200)$ compared with the NE zone with only 4,400 [20] even though they have almost same population size. The situation is the same for eye health workers [19] and may, in part, explain the difference in the prevalence of blindness by GPZs.

Low productivity by the ophthalmologists and other eye care workers further worsens the situation. In 2006, the cataract surgical rate in Nigeria was only about 300 [19] instead of the target of 2,000 for Africa. This is compounded by the less than optimal quality of the eye services in the country, as demonstrated in this study where less than a third of cataract operated eyes had a 'good outcome', even after optical correction the proportion with 'good outcomes' was only $56.8 \%$, much below the $90 \%$ recommended by WHO. Poor outcomes may be due to a variety of factors including late presentation for surgery and ocular co-morbidity. However, provider-related factors such as inadequate equipment for pre-operative assessment and microsurgery also exist. Thus, a recent review of the Nigerian health system had highlighted lack of optimal enabling environment for health workers and poor motivational strategies. [20]

Other factors that may affect effective and quality eye care include weak healthcare system, under funding and poverty. The lack of eye care services and relatively poor outcomes may be reasons why cataract blind seek traditional healers, even though outcomes are bad. The Nigerian healthcare system assessment (2008) [20] stated that coverage of most key preventive and curative health services was relatively low and was compounded by wide disparities between GPZs, and rural-urban socioeconomic differences, with much poorer coverage in many parts of the northern GPZs. This probably explains the higher prevalence of blindness in the northern zones.

Health financing in Nigeria is very low. At the national level, the estimated health expenditure per capita is $\$ 131$ : this is below the global average of $\$ 863$. [20] State governments provide most secondary and primary care but their health expenditure per capita is often less than $\$ 4$. [20] As such, the total expenditure on health as $\%$ of GDP for Nigeria is only $6.6 \%$ against a global average of $9.7 \%$. [21]

In 2010 , the federal budget allocated only $3.4 \%$ to health but eye care received less that $0.005 \%$ of the budget. [22]

\section{Acknowledgements}

The authors thank the Nigerian Federal ministry of Health, states, local governments, and the National Eye center Kaduna Nigeria. We are also indebted to many Nigerian ophthalmologists, nurses, data clerks, accountants and secretaries and other field work staff who contributed to the success for the survey. We express our appreciation to Mrs. Oye Quaye for managing the finances for the study, Mr Auwal Shehu and Mr Dania Charles for data entry.

\section{References}

1 New WHO blindness estimates. Available from: http://www.who.int/blindness/en/index.html. [Last accessed on 2011 Feb 26].

2 Polack S, Eusebio C, Mathenge W, Wadud Z, Mamunur AK, Fletcher A, et al. The impact of cataract surgery on health related quality of life in Kenya, the Philippines, and Bangladesh. Ophthalmic Epidemiol 2010;17:387-99.

Frick KD, Foster A, Bah M, Faal H. Analysis of costs and benefits of the Gambian Eye Care Program. Arch Ophthalmol 2005;123:239-43.

Frick KD, Foster A. The magnitude and cost of global blindness: An increasing problem that can be alleviated. Am J Ophthalmol 2003;135:471-6.

Blindness poverty and development: Impact of Vision 2020 on the UN millennium development goals. IAPB/Vision 2002 office London School of Hygiene and Tropical Medicine, Keppel street, London.

Available from: http://www.population.gov.ng/files/nationafinal.pdf. [Last accessed on $2011 \mathrm{Feb} 20]$.

7 Dineen B, Gilbert CE, Rabiu M, Kyari F, Mahdi AM, Abubakar T, et al. The Nigerian national blindness and visual impairment survey: Rationale, objectives and detailed methodology. BMC Ophthalmol 2008;8:17.

8 Kyari F, Gudlavalleti MV, Sivsubramaniam S, Gilbert CE, Abdull MM, Entekume G, et al.; Nigeria National Blindness and Visual Impairment Study Group. Prevalence of Blindness and Visual Impairment in Nigeria: The national blindness and visual impairment survey. Invest Ophthalmol Vis Sci 2009;50:2033-9.

Abdull MM, Sivasubramaniam S, Murthy GV, Gilbert C, Abubakar T, Ezelum C, et al.; Nigeria National Blindness and Visual Impairment Study Group. Causes of blindness and visual impairment in Nigeria: The Nigeria national blindness and visual impairment survey. Invest Ophthalmol Vis Sci 2009;50:4114-20.

10 Gilbert CE, Murthy GV, Sivasubramaniam S, Kyari F, Imam A, Rabiu MM, et al. Couching in Nigeria: Prevalence, risk factors and visual acuity outcomes. Ophthalmic Epidemiol 2010;17:269-75.

11 Imam AU, Gilbert CE, Sivasubramaniam S, Murthy GV, Maini R, Rabiu MM; Nigeria National Blindness and Visual Impairment Study Group. Outcome of cataract surgery in Nigeria: Visual acuity, autorefraction, and optimal intraocular lens powers-results from the Nigeria National Survey. Ophthalmology 2011;118:719-24.

Mehra V, Minassian DC. A rapid method of grading cataract in epidemiological studies and eye surveys. Br J Ophthalmol 1988;72:801-3.

13 Chylack LT Jr, Wolfe JK, Singer DM, Leske MC, Bullimore MA, Bailey IL, et al. The Lens Opacities Classification System III. The Longitudinal Study of Cataract Study Group. Arch Ophthalmol 1993;111:831-6.

World Health Organization. The management of low vision in children. Report of a WHO consultation, Bangkok, July 1992. Geneva: 1993.

Murthy GV, Gupta SK, Bachani D, Jose R, John N. Current estimates of blindness in India. Br J Ophthalmol 2005;89:257-60.

Jadoon MZ, Dineen B, Bourne RR, Shah SP, Khan MA, Johnson GJ, et al. Prevalence of blindness and visual impairment in Pakistan: The Pakistan National Blindness and Visual Impairment Survey. Invest Ophthalmol Vis Sci 2006;:47:4749-55.

Berhane Y, Worku A, Bejiga A. Survey Report National Survey on Blindness, Low Vision and Trachoma in Ethiopia. Federal Ministry of Health of Addis Ababa: Ethiopia; September, 2006.

18 Resnikoff S, Pascolini D, Etya'ale D, Kocur I, Pararajasegaram R, Pokharel GP, et al. Global data on visual impairment in the year 2002. Bull World Health Organ 2004;82:84451.

Strategic plan for Nigeria: Vision 2020-The Right to Sight 2007-2011. Federal Ministry of Health: Abuja; 2007

Gilbert K, Fleisher L, Kariisa E, Arur A, Parsa S, Paina L, et al. Nigeria Health System Assessment 2008. Abt Associates Inc.; April 2009.

Available from: http://www.globalhealthfacts.org/topic.jsp?i=66. [Last accessed on 2011 Jan 11].

Olowu B. Elimination of avoidable blindness: Nigeria Institute of Policy and Strategic Studies (NIPSS) Kuru, Plateau State, dissertation 2008. 